Çukurova Üniversitesi Mühendislik Mimarlık Fakültesi Dergisi, 31(2), ss. 293-306, Aralık 2016

Çukurova University Journal of the Faculty of Engineering and Architecture, 31(2), pp. 293-306, December 2016

\title{
KB Türkiye (Şile-İstanbul) Entomozoacean Ostrakodları
}

\author{
Emine ŞEKER ZOR ${ }^{* 1}$, Atike NAZİ ${ }^{1}$ \\ ${ }^{1}$ Çukurova Üniversitesi, Mühendislik Mimarlık Fakültesi, Jeoloji Mühendisliği Bölümü, Adana
}

Geliş tarihi: 08.06.2016 Kabul tarihi: 23.11.2016

Öz

$\mathrm{Bu}$ çalışmada Kuzeybatı Türkiye Şile-İstanbul bölgesinde yüzeyleyen Büyükada Formasyonunun Yörükali Üyesi ostrakodları çalışılmıştır. Sözü edilen birimden Yörükali ve Karamandere kesitleri ölçülmüsşür. Alınan örneklerde Myodocopid familyasına ait olan Entomozoacean (pelajik parmak izi) ostrakodları çalışılmıştır. Kesitlerde Entomoprimitia Kummerow; Nehdentomis Matern; Rabienella Gründel; Richterina Gürich; Richterina (Volkina) Rabien; Waldeckella Rabien; Kuzminaella Tschigova; Franklinella Stewart and Hendrix; Nehdentomis (Matern), ostrakod cinsleri tanımlanmıştır. Saptanan bu türler Frasniyen yaşlı Entomoprimitia sartenaeri Zonu'nu (= variostriata Zone sensu Rabien) karakterize etmektedir. Yörükali Üyesi içinde bulunan Geç Devoniyen entomozoacean ostrakodları, Polonya/Holy Cross Dağları, Almanya/Rheinische Schiefergebirge, Kuzey Fransa-Belçika/Ardenler, Volga-Ural Bölgesi ve Güney Çin'de bilinmektedir.

Anahtar Kelimeler: Ostrakod, Entomozoacean, Frasniyen, İstanbul/Türkiye

\section{Entomozoacean Ostracodes of NW Turkey (Şile -İstanbul)}

\begin{abstract}
Yörükali and Karamendere sections were measured in Yörükali member of Büyükada formation surfaced in the Şile-İstanbul region of NW Turkey. 16 paleontologic samples are researched from these sections. Entomozoacean ostracodes (pelagic so-called fingerprint ostracodes) of Myodocopid family were studied. In this study, 8 genera and 13 species of the Entomozoacean type ostracodes were identified in the Late Devonian. These identified species correspond to Entomoprimitia sartenaeri zone (= variostriata Zone sensu Rabien). These entomozoacean zone and ostracodes indicate that there were faunal relations with Poland/Holy Cross Mountains, Germany/Rheinische Schiefergebirge, N France-Belgium/Ardennes, Volgo-Ural Region and South China in Late Devonian.
\end{abstract}

Keywords: Ostracodes, Entomozoacea, Frasnian, İstanbul/Türkiye

\footnotetext{
*Sorumlu yazar (Corresponding author): Emine ŞEKER ZOR, emiseker@gmail.com
} 


\section{GíRiș}

Ostrakodlar ekolojik/paleoekolojik olarak önemli Crustacean'lardır. Dünya'da 1954 yılından bu yana Entomozocean ostrakod topluluğu çalışılmaya başlanmıştır. Stratigrafik olarak önemli olan bu ostrakodların yaşam biçimleri ve ortamları hakkında hala araştırmacılar arasında büyük tartışmalar bulunmaktadır. Türkiye'de Paleozoyik için karakteristik olan Entomozoacean grubu ostrakodlar yakın geçmişte çalışılmaya başlanmıştır $[1,2]$.

Türkiye'nin Kuzey batısında yer alan İstanbul Paleozoyik istifi birçok konuda ayrıntılı olarak incelenmiştir [3-14]. Farklı fosil grupları olarak paleontolojik amaçlı çok sayıda çalışma da yapılmıştır [1,-3,5,15-39].

$\mathrm{Bu}$ çalışmanın amacı, İstanbul Paleozoyik istifindeki Devoniyen yaşlı Büyükada Formasyonu Entomozoacean ostrakod topluluğunun biyostratigrafisini ve paleocoğrafyasını ortaya koymaktır.

\section{MATERYAL VE METOT}

Çalışmanın materyalini, İstanbul iline bağlı Şile ilçesinin Darlık bölgesinde mostra veren Büyükada Formasyonu, Yörükali Üyesi birimlerinden ölçülen kesitlerden derlenen fosilli ayrışmış ve sert kayaç numuneleri oluşturmaktadır (Şekil 1). Araştırmada, 2 adet stratigrafik kesit ölçülerek toplam 16 paleontolojik örnek alınmıştır.

$\mathrm{Bu}$ çalışmada, araziden alınan paleontolojik örnekler; herhangi bir işlem görmeden, tabakalanma yüzeyine paralel olarak ayrılarak stereomikroskop altında doğrudan incelenmiştir. Entomozoacean ostrakodların, kayaçta bulunan fosilleri, iç ve dış kalıpların bazı morfolojik özellikleri incelenerek cins ve tür tayinleri yapılmaktadır. $\mathrm{Bu}$ tayinler yapılırken Şekil 2 ve Şekil 3'de verilen tipik özellikleri (dış ve iç kavkı süsleri, dikenler, kas izi vb.) dikkate alınarak tanımlanır. Entomozoacean ostrakodların fotoğrafları entegre soğuk 1şık kaynağına sahip Leica DFC320 model mikroskop ile çekilerek Levha 1-2 hazırlanmıştır.

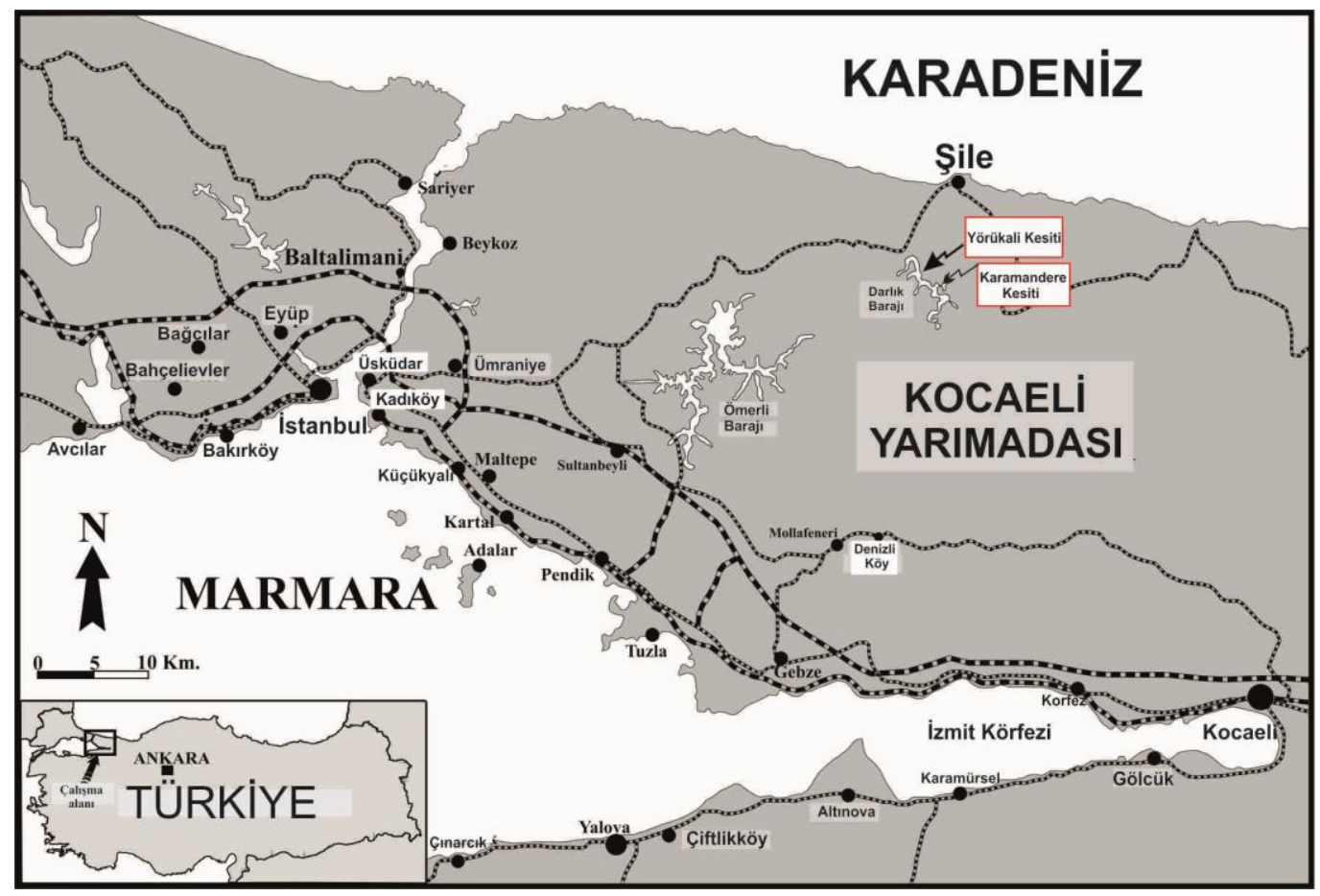

Şekil 1. Çalışma alanın yer bulduru haritası 


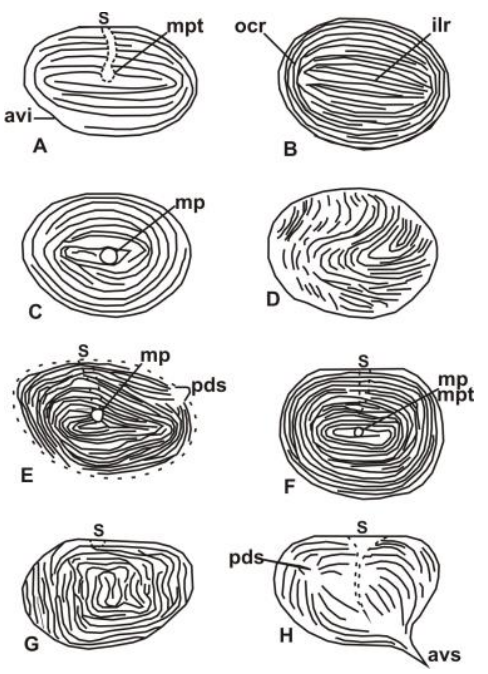

avi: Ön-karın kenar girinti (Antero-ventral indentation of marjin)

mpt: Kas çukuru (Muscle patch)

s: Oluk (Sulcus)

ocr: Dış konsantrik çizgiler (Outer concentric rib)

ilr: İç boyuna çizgiler (İnner longitudinal rib)

mp: Kas izi (Muscle pit)

pds: Arka-sırt dikeni (Postero-dorsal spine)

avs: Ön-karın dikeni (Antero-ventral spine)

Şekil 2. Tipik Geç Devoniyen-Karbonifer Entomozoacean ostrakod'ların kavkılarındaki dış hat ve çizgileri [40].

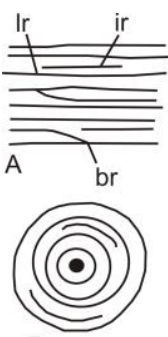

D

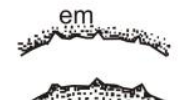

G
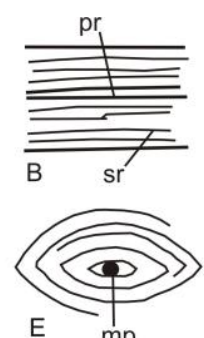

E $\quad m p$

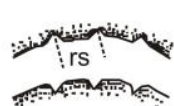

$\mathrm{H}$
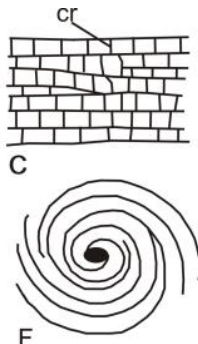

$\mathrm{F}$

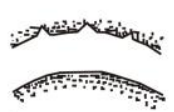

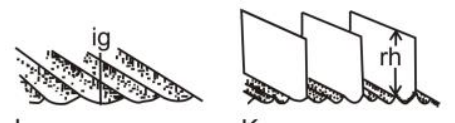

$\mathrm{K}$

A: Kısa iç çizgiler (ir) ve yatay çizgiler (lr)

B: Birincil (pr) ve ikincil (sr) çizgilerin arasında farklılaşmış yatay çizgiler

C: Düşey çizgilerle (cr) bölünmüş yatay çizgiler (lr)

D: Dairesel consantrik çizgiler

E: Merceksi contrik çizgiler

F: Kas izi (mp) çevresinde spiral çizgiler

G: Dış kalıp (em) ve iç kalıp (im)

H: Yer değiştirmiş süslerle iç ve dış kalıplar (rs,

İ: Düz iç kalıpla süslü dış kalıp (rs

J: Çizgiler arası çukurluklu ayrılmış normal çizgiler

K: İki normal çizgiler yükseltiyle yayılmış

Şekil 3. Tipik Geç Devoniyen-Karbonifer Entomozoacean ostrakod'ların kavkılarındaki çizgi terminolojisi [40].

\section{LITOSTRATIGRAFI}

$\mathrm{Bu}$ araştırma, İstanbul Paleozoyik istifinin Denizliköy grubuna ait Büyükada formasyonu Yörükali Üye'si birimlerinde yapılmıştır. Bu nedenle Büyükada Formasyonu ve Yörükali Üyesi ayrıntılı özellikleri ve diğer birimlerle olan ilişkileri aşă̆ıda verilmiştir $[9,10]$.

\subsection{Büyükada Formasyonu}

Tanım, ad ve dăğllım: Başlıca afanitik (mikrokristalli) kireçtaşı, yumrulu kireçtaşı, kalkerli, şeyl, lidit (radyolarit-opalimsi çört) ve grovaklardan oluşan birim ilk kez [30] tarafindan "Büyükada Formasyonu" olarak adlanmıştır. Adını Büyük Ada'dan alan birimin ayrıntılı tanımı [5]'da 
yapılmıştır. Bu çalışmada, grovaklardan oluşan en üstteki Küyükyalı üyesi Baltalimanı Formasyonu'na dahil edilerek incelenmiştir. Formasyon, Kocaeli yarımadası'nın bat kesimlerinde yaygın olarak yüzeyler. Tip kesit ve Tip yer: Tip yeri ve tip kesiti olmayan birim için [5], üyelere ait referans ve tip kesitler verir. Şile güneyindeki Korucu köyü güneydoğusu (F23d; D: 16600-K: 53100 ile D: 16850-K:53300 aras1) ile Gebze kuzeydoğusundaki Denizliköy dolayı (G23a D:13100-K:31000 ile D:13500-K:29000 aras1) birim için tip kesit yeri olarak önerilir. Kaya türü özellikleri: Birim altta kireçtaşı, ortada şeyl-çört ardalanması ve üstte de genellikle ince yumrulu kireçtaşından oluşur. Ayrıntılı tanımları üyelerde verilen bu kaya türleri Bostancı üyesi, Yörükali üyesi ve Ayineburnu üyesi olarak adlanmıştır [5, 30]. Dokanak ilişkileri: Büyükada Formasyonu alta Kartal, üstte Baltalimanı formasyonları ile dereceli geçişlidir. Kalınlık ve Yanal değişim: Birimin kalınlığg $200 \mathrm{~m}$ dolayında olup, kendisini oluşturan kaya türleri arasında yanal ve dikey yönde değişim sunar. Fosil kapsamı ve yaş: Büyükada Formasyonu'nun yaşı, önceki araştırmacıların yaş bulguları irdelenerek Geç Eyfeliyen-Fameniyen (Orta-Geç Devoniyen) olarak benimsenmiştir. Ortam yorumu: Formasyonu oluşturan kaya türleri ramp (ramp tipi şelf) ortamının kıta yamacına yakın olan kesimi ile kıta yamacında çökelmiş olmalıdır [13]. Deneştirme: Birim çalışma alanında "Fosilli Seri" [15] ve "Böbreksi Kireçtaş1-Çörtşist Seri” [41] içinde; "Bänderschifer-Fazies" ve "NierenkalkHorizont" adlarıyla [43]; "Böbreksi kireçtaşı (Nierenkalk) adı altında [42, 43]; Ara fasiyes içinde "yumrulu Kireçtaşı" ve "Kireçtaşı" adlarıyla; [44] "Yumrulu kalkerler [19] ve "Denizli tabakaları" [4] adları altında "Nodüler ve Çörtlü Kireçtaşları [45] ve "Tuzla Formasyonu" [6, 11] adlarıyla incelenmiştir. Formasyonun Batı Pontidler'de deneştirebileceği bir birim bilinmemektedir.

Yörükali Üyesi: Başlıca liditlerden oluşan birim, [5] tarafından Büyükada Formasyonu kapsamında "Yörükali üyesi" olarak adlanmıştır. Adını Büyük Ada batısındaki (Dil Burnu güneydoğusu) Yörükali koyundan alan birim, Tuzla Yarımadacığı'nın doğu kıyısı ile Korucu Köyü
(F23d) güneydoğusundaki Kışla Sırtı güneyinde, Gebze kuzeyinde Organize Sanayi kuzeydoğusunda, Denizliköy kuzeydoğusunda tipik yüzlekler sunar. Üyenin tip kesiti Yörükali güneyindedir [5]. Birim gri, pembe ve sarıms1 kahverenkli, silisifiye şeyl ile siyah renkli çörtradyolarit ardalanmasından oluşur. Laminalanmalı olan şeyl ve çörtler, nadir olarak siyah kireçtaş1 aratabakaları içerir. Birim içinde seyrek olarak gözlenen 2-3 cm çapındaki disk şekilli çört yumruları radyolarya fosili içerir. Kayma-oturma ve tektonik etki nedeniyle birim oldukça kıvrımlıdır. Denizliköy kuzeyindeki Yelken Tepe ve civarında olduğu gibi, üyenin yoğun lidit-çört içeren seviyeleri Baltalimanı Formasyonu ile büyük benzerlik gösterir. Pembe-mor rengin (yüzeyde bazen $15-20 \quad \mathrm{~cm}^{2}$ lik bir alan büyüklüğünde) varlığı, içerdiği yumruların yassı şekilli oluşu ve silisifiye şeyl içermesi ile Baltalimanı Formasyonu'ndan kolaylıkla ayrılır [10].

Birim altta Bostanc1, üstte ise Ayineburnu üyeleri ile dereceli geçişlidir. Üyenin kalınlığı değişken olup, yer yer 100 metreye varan kalınlığa ulaşır.

Birimdeki yassı-yarı yuvarlak silis yumrularından Erken Devoniyen-Geç Permiyen yaş aralığını temsil eden Stigmophaerostylus sp. ve Trilonch sp. gibi radyolarya fosilleri tanımlanmıştır [26]. Ancak, tanımlayan araştırmacılar, faunada Albeillit'lerin olmaması nedeniyle, birimin yaşı [46] tarafindan olası Devoniyen olarak benimsenmiştir. Üyenin yaşı, stratigrafik konumu (altta Bostancı üyesi Geç Eyfeliyen-üstte Ayineburnu üyesi Fameniyen) göz önünde bulundurularak Givesiyen-Frasniyen olarak benimsenmiştir. Üyenin çökelme ortamı, rampın (ramp tipi şelfin) önündeki kıta yamacı olmalıdır $[6,11]$.

Birim çalışma alanında "Böbreksi Kireçtaş1Çörtşist Seri (Die Nierenkalk-KieselschieferSerie)" [3,41] içinde; "Yelkentepe Tabakaları (Yelken Tepe-Schichten)" [4] adiyla; Tuzla formasyonu içinde "Yörükali üyesi" $[6,11]$ adı altında incelenmiştir. 


\section{4. ÖLÇÜLÜ KESITTLER VE OSTRAKOD TOPLULUĞU}

\subsection{Yörükali Kesiti ve Entomozoacean Ostrakodları}

İnceleme alanında Yörükali kesiti 1/25.000 ölçekli F22c3 paftasinda 0718063E 4552970N koordinatları ile başlar 0716737E, $4553035 \mathrm{~N}$ koordinatları ile son bulur. $\mathrm{Bu}$ kesit 23,5 m kalınlıkta olup toplam 11 paleontolojik örnek derlenmiştir.

Kesit, Büyükada Formasyonunun Yörükali üyesi içerisindeki çökellerden [33]'de belirtilen seviyeleri de içine alacak şekilde detaylı olarak tekrar ölçülmüştür. Yörükali ölçülü kesiti, koyu gri-siyah, ince-orta tabakalı, yer yer laminalı sparit damarlı mikritik kireçtaşı içerikli Büyükada Formasyonun Bostancı üyesi ile başlamakta, siyah, bozuşma rengi sarı, sarımsı kahverengi, ince orta tabakalı, laminalı çört-lidit ile devam etmektedir. $\mathrm{Bu}$ seviyenin üzerine koyu gri siyah, ince-orta tabakalı, yer yer laminalı sparit damarlı mikritik kireçtaşı ve üzerine siyah, sarımsı kahverengi ince tabakalı çört gelmektedir. Bu serinin üzerine yine gri kil rengi, bozunma rengi sar1-sarımsı kahverengi çok ince tabakalı ve laminalı (pijama benzeri) silttaşı, silisifiye şeyl ardalanması, gözenekli ve gevşek katmanlanmalar gelmektedir (Şekil 4).

Bunların üzerine bozuşma rengi sarı, sarımsı kahverengi, laminalı çört üzerine yeşil, yeşilimsi gri, gri mavi, bozulma rengi sar1, sarımsı kahverengi ince tabakalı laminalı silttaşı, silisifiye şeyl ardalanması gelmektedir. Yeşilimsi gri bozunma rengi kahverengi çok ince taneli mikalı çok ince silttaşı üzerine sarımsı gri ve sarımsı kahverengi, yassı çört nodüllü çok bozuşmuş çört tabakası gelmektedir. Birim üstte doğru bantlı yap1 kazanmakta ve yumrulu kireçtaşı ile kesit son bulmaktadır.

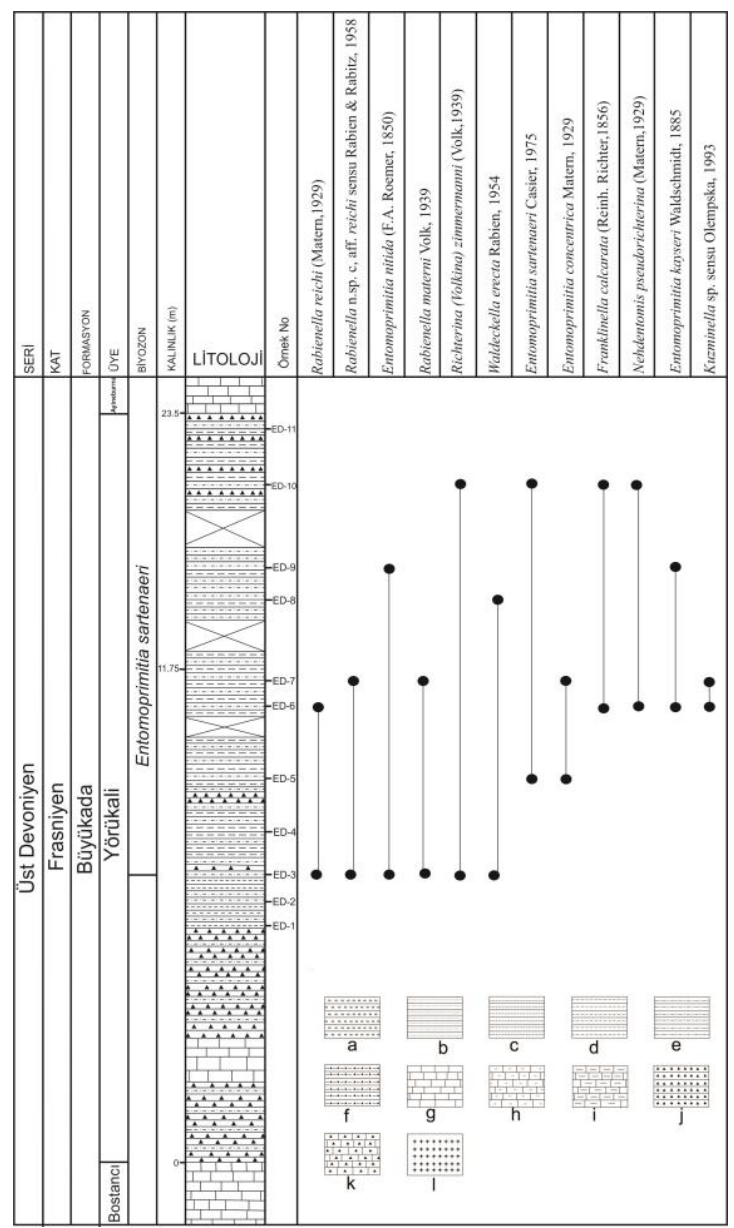

Şekil 4. Yörükali kesiti ve ostrakod dağılımı, Litolojik açıklamalar: a. Çakıltaşı, b. Kumtaşı, c. Kiltaşı, d. Silttaşı, e. Yumrulu silttaşı, f. Silislesmiş şeyl, g. Kireçtaş1, h. Yumrulu kireçtaşı, i. Killikireçtaşı, j. Çört, k. Çörtlü kireçtaşı, 1. Granit

Yörükali kesitinde Cladocopina alttakıma ait Entomozoacea Süperfamilya'sından 8 cins ve 13 tür tayin edilmiştir. Geç Frasniyen'de Entomoprimitia sartenaeri Zonunda (=variostriata Zone sensu Rabien); Entomoprimitia Kummerow; Nehdentomis Matern; Rabienella Gründel; Richterina Gürich; Richterina (Volkina) Rabien; Waldeckella Rabien; Kuzminaella Tschigova; Franklinella Stewart and Hendrix ostrakod cinsleri tanımlanmıştır. 


\subsection{Karamandere Kesiti ve Entomozoacean Ostrakodları}

Karamandere ölçülü stratigrafik kesiti 1/25.000 ölçekli İstanbul F22c3 paftası 071865E ve $4554268 \mathrm{~N}$ koordinatlarıla başlar ve $0718196 \mathrm{E}$ $4554120 \mathrm{~N}$ koordinatı ile ölçülü stratigrafik kesit son bulur.

Karamandere kesitinin 0-3 m arası koyu gri-siyah, ince-orta tabakalı, sparit damarlı mikritik kireçtaşı ile başlamaktadır (Şekil 5). 3-18 m arası siyah, ince tabakalı, laminalı çört-lidit üzerine $3 \mathrm{~m}$ koyu gri-siyah, mikritik kireçtaşı gelmektedir. Yaklaşık 9m örtü tabakasından sonra $7 \mathrm{~m}$ kalınlıkta siyah, bozuşma rengi sarımsı kahverengi, ince tabakalı, laminalı çört ile siyah, çok ince tabakalı silisifiye şeyl bulunmaktadır. Bu tabakaların üzerine $2 \mathrm{~m}$ örtü bulunmaktadır. Bunun üzerine yeniden ince tabakalı laminalı çört ile çok ince tabakalı silisifiye şeyl ardalanması ve $2 \mathrm{~m}$ örtü tabakası gelmektedir. $\mathrm{Bu}$ tabakalardan hemen sonra gri, yeşilimsi gri, grimsi yeşil, mikalı silisifiye şeyl ve çok ince taneli silttaşı vardır ve bantlaşma yapısı göstermektedir. $\mathrm{Bu}$ seviyeden itibaren örneklemeye bulunmaktadır. Yaklaşık $7 \mathrm{~m}$ örtüden sonra $3 \mathrm{~m}$ siyah çört ve bantlı yapı üzerine yeniden yaklaşık $4 \mathrm{~m}$ kalınlığında örtü tabakası gelmektedir. Kesit grimsi-yeşil ve boz renkli ince tabakalı bantlı silttaşı ve silisifiye şeyl ile son bulmaktadır.

Kesit içerisinde, 5 paleontolojik örnek derlenmiş̧tir. Kalınlığı ise 61 m'dir. Karamandere kesitinde Cladocopina alttakıma ait Entomozoacea Süperfamilya'sından 4 cins ve 5 tür tayin edilmiştir. Karamandere kesitinde yapılan çalıșmalarda Richterina (Volkina) zimmermanni Volk; Waldeckella erecta Rabien; Franklinella sp., Nehdentomis pseudorichterina Matern; Entomoprimitia kayseri Waldschmidt, türleri bulunmuştur Fosil fotoğrafları Levha 1 ve 2 'de verilmiştir.

\section{BIIYOSTRATIGRAFI}

Devoniyen, Avrupa'da İspanya, Almanya, Fransa'da; Asya'da ise Çin'de konodont, ammonit ve ostrakod zonlarına bağlı detaylı olarak incelenmiş; kronostratigrafik ve biyostratigrafik ayrımlar yapılmıştır. Bu zonların karşılaştırılmaları [47]'e göre Şekil 6'de verilmiştir

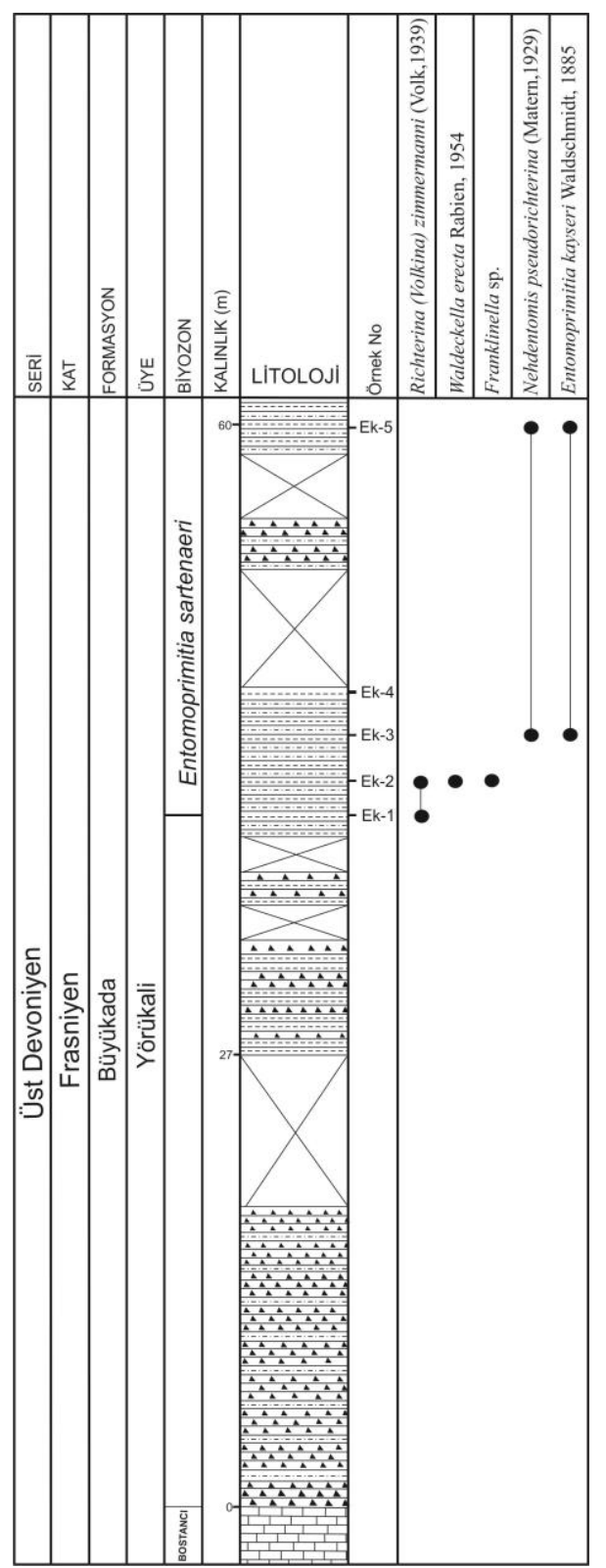

Şekil 5. Karamandere kesiti ve ostrakod dağılımı

Bu çalışmada Entomozocean ostrakod topluluğuna göre Entomoprimitia sartenaeri Zonu (= variostriata Zone sensu Rabien) ayırtlanmıştır. 
Entomoprimitia sartenaeri Zonu (= variostriata Zonu sensu Rabien)

Kategori : Topluluk Zonu

Yaş : Geç Frasniyen

Yazar : Casier [49]

Tanım : Rabienella cinsi'nin volki, schmidti, ve reichi türleri ilk kez ortaya çıkmıştır [17].

Yaygın Cins ve Türler: Entomoprimitia concentrica Matern; Entomoprimitia nitida (F.A. Roemer); Entomoprimitia kayseri Waldschmidt;
Entomoprimitia sartenaeri Casier; Nehdentomis pseudorichterina (Matern); Rabienella reichi (Matern), Rabienella n. sp. c, aff. reichi sensu Rabien \& Rabitz; Rabienella materni Volk; Richterina (Volkina) zimmermanni (Volk); Waldeckella erecta Rabien; Franklinella calcarata (Reinh. Richter); Kuzminella sp. sensu Olempska [50].

Karşılaştırma ve Yorum : $\mathrm{Bu}$ zon Casier [49] tarafından Belçika'da Boussu-en-Fagne bölgesinde Matagne Formasyonun'da tanımlanmıştır [39,14].

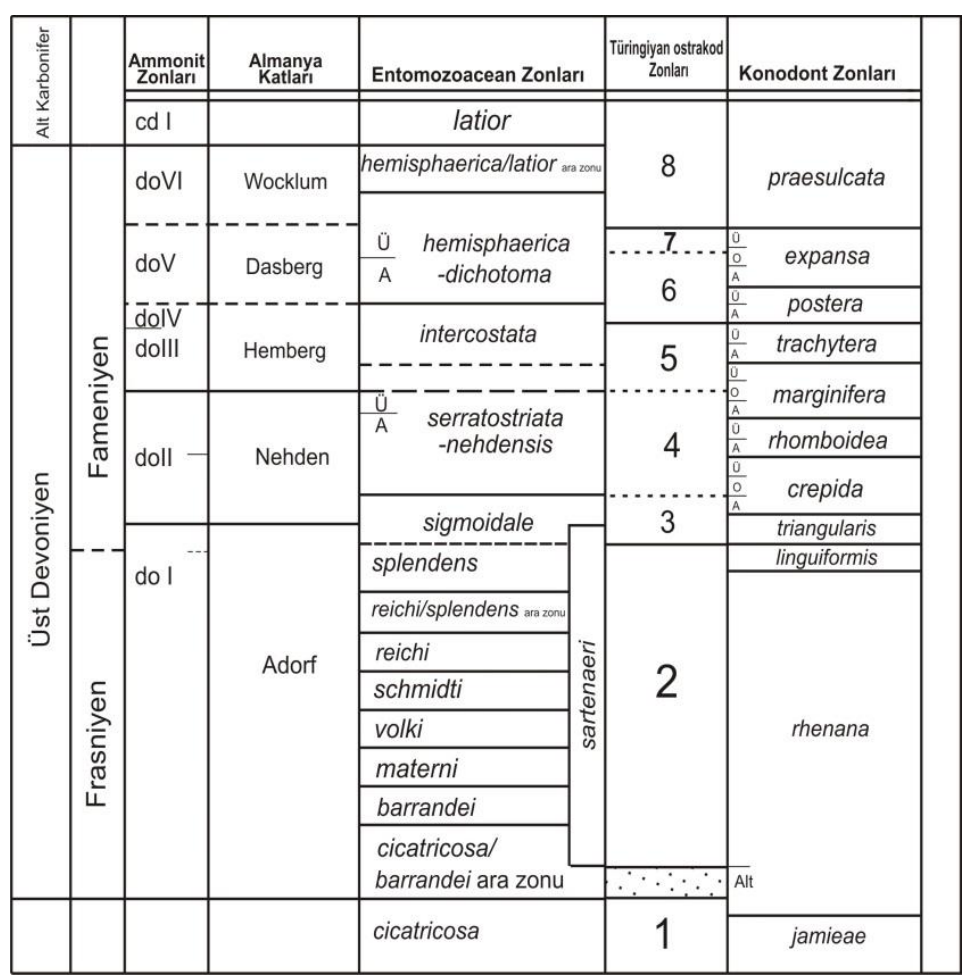

Şekil 6. Üst Devoniyen biyostratigrafik korelasyon $[47,51,52]$

\section{PALEOEKOLOJI VE PALEOCOGRAFYA}

Devoniyen ostrakodları marn ve kireçtaşları içerisinde kavkı veya kapak olarak; şeyl, kumtaşı ve bozunmuş kireçtaşlarında ise iç ve dış kalıp olarak bulunmaktadırlar. Devoniyen ostrakodları çoğunlukla denizel sedimanlarda bulunur. Üç ana denizel ekotip veya ekotopluluk öngörülmüştür [14,53-57]. Bu topluluklar Şekil 7'de gösterilmiştir.

$\mathrm{Bu}$ çalışmada entomozoacean ostrakod topluluğu şeyl ve marnların arasından fosilin kendisi, iç ve dış kalıpları olarak bulunmuştur. 
Bölgede yapılan daha önceki çalışmalardan [13]'da Büyükada Formasyonuna ait Yörükali üyesinin pelajik ortamda çökeldiğinden bahsedilmiştir. $\mathrm{Bu}$ çalışmada Yörükali ve Karamandere kesitlerinden alınan örneklerde Entomoprimitia Kummerow; Nehdentomis Matern; Rabienella Gründel; Richterina Gürich; Richterina (Volkina) Rabien; Waldeckella Rabien; Kuzminaella Tschigova; Franklinella Stewart and
Hendrix gibi entomozoacean cinslerinin varlığ daha önceki çalışmaların sonuçunu destekler niteliktedir. $\mathrm{Bu}$ çalışmada saptanan Entomozoacean ostrakodlar önceki çalışmalarla karşılaştırılarak, Polonya/Holy Cross Dağları, Almanya/(Ren masifi, Harz, Türingiya), Kuzey Fransa-Belçika (Ardenler), Volgo-Ural bölgesi ve Güney Çin'de ve Türkiye'de bulunmuştur (Şekil 8).

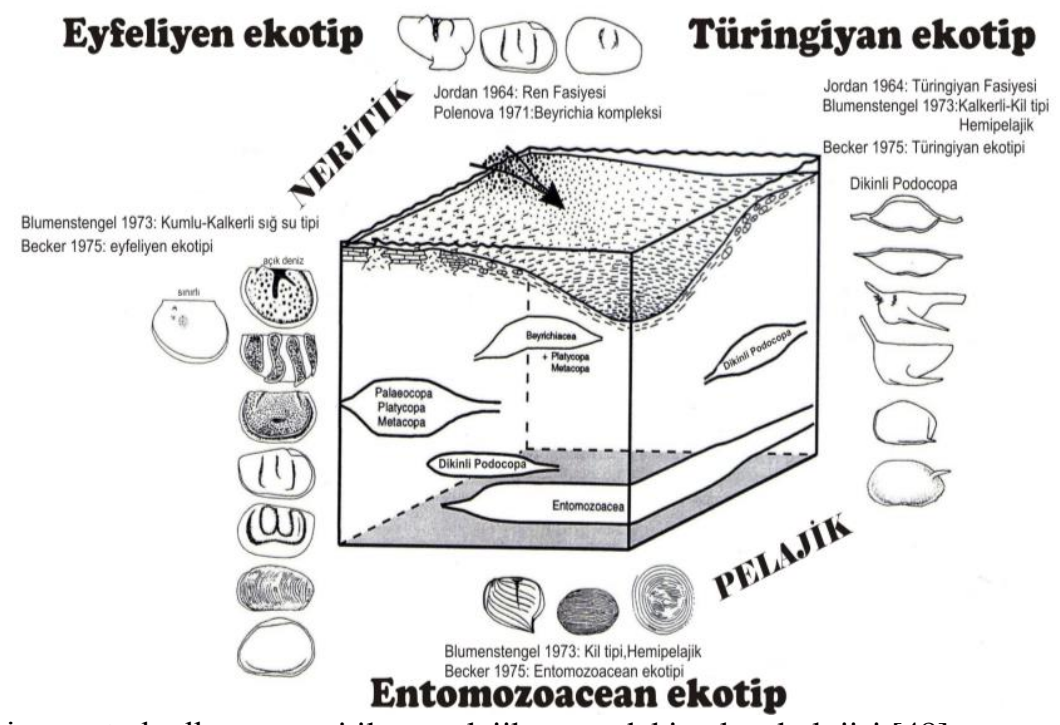

Şekil 7. Devoniyen ostrakodlarının neritik ve pelajik ortamdaki paleoekolojisi [48]

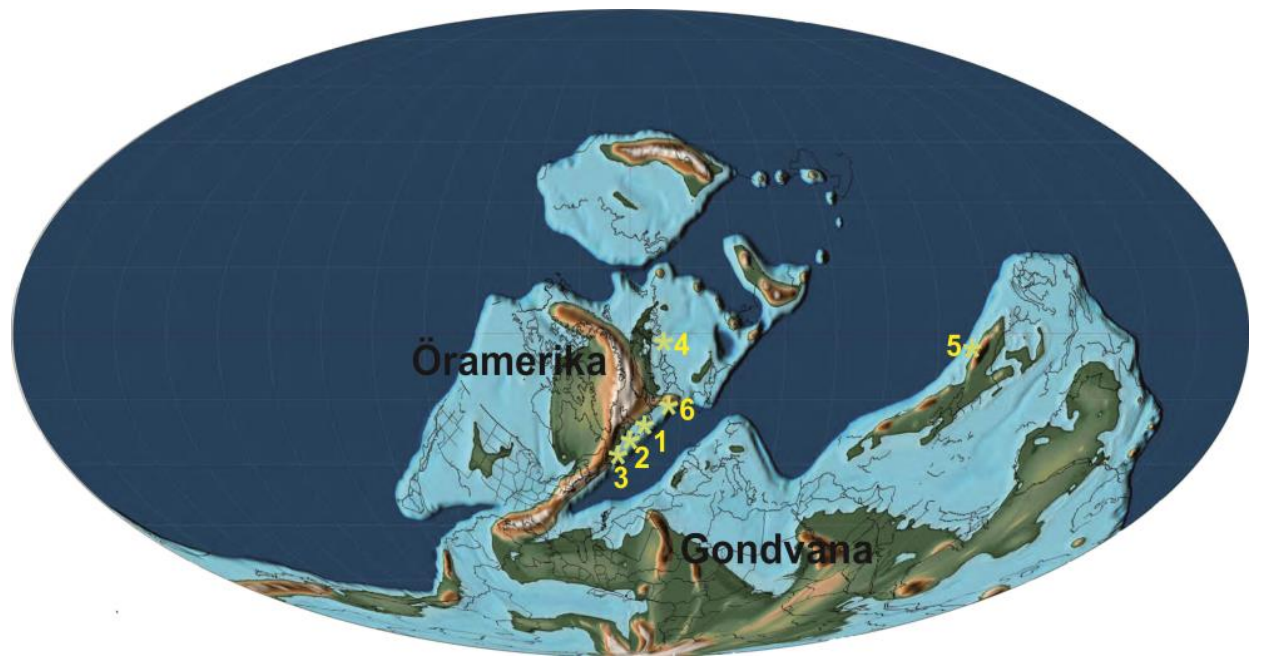

Şekil 8. Geç Frasniyen paleocoğrafya haritası üzerinde entomozoacean faunasının bulunduğu yerler [6]'dan değişstirilerek. 1. Polanya/Holy Cross Dağları, 2. Almanya/Ren Masifi, 3. K FransaBelçika/Ardenler, 4. Volgo-Ural Bölgesi, 5. Güney Çin, 6. Türkiye 


\section{SONUÇLAR}

Bu çalışmada, Yörükali ve Karamandere ölçülü stratigrafi kesitlerinden alınan örneklerde ostrakodlardan Cladocopina alttakıma ait Entomozoacea süperfamilya'sından 8 cins ve 13 tür tayin edilmiştir (Levha 1, 2).

Entomozocean ostrakod topluluğuna göre ve Entomoprimitia sartenaeri Zonu (= variostriata Zone sensu Rabien) ayırtlanmıştır [57, 59].

Paleobiyocoğrafik olarak bulunan entomozoacean ostrakodlar, Polonya/Holy Cross Dağları, Almanya/ (Ren masifi, Harz, Türingiya) Kuzey Fransa-Belçika (Ardenler), Volga-Ural bölgesi ve Güney Çin ile ilişkili olduğu görülmüştür [60].

Entomozoacean ostrakod topluluğunun yaşam ortamları araştırmacılar tarafından hala tartışılsa da pelajik ortamda yaşadıkları büyük oranda kabul görmüştür [6]. Daha önceki çalışmalarda Büyükada Formasyonuna ait Yörükali üyesi'nin açıkdeniz de çökelmiş olduğu bilinmektedir. Bu çalışmada bulunan ostrakodlarda bu görüşü desteklemektedir.

\section{TEŞEKKÜR}

$\mathrm{Bu}$ çalışmaya katkılarından dolayı sayın Emekli Yüksek Jeoloji Mühendisi İbrahim GEDİK (MTA) ve yapılan tez çalışmasını MMF2009YL56 proje numarası ile destekleyen

ÇÜBAP (Çukurova Üniversitesi Rektörlüğü Bilimsel Araştırma Projeleri Koordinasyon Birimi)'a teşekkür ederiz.

\section{KAYNAKLAR}

1. Nazik, A., Groos-Uffenorde, H., 2016. Notes on beyrichiacean ostracodes from the Early Devonian of NW Turkey and Their Palaeobiogeographical Relations, Turkish Journal Of Earth Sciences, vol.25, pp.201-226.

2. Nazik, A., Groos-Uffenorde, H., Şeker, E., Yalçın, M.N., Wilde. V., Schindler, E., 2015. Orta-Doğu Toroslar ve KB Anadolu Devoniyen Ostrakodlarının Biyostratigrafisi, Paleoekolojisi ve Paleobiyocağrafyası, İstanbul
Üniversitesi'nde Jeoloji'nin 100. Y1l Sempozyumu \& Mezunlar Günü Bildiri Kitabı, 674-675, İstanbul.

3. Özgül, N., 2012. Stratigraphy and Some Structural Features of the Istanbul Palaeozoic. Turkish Journal of Earth Sciences 21, 817-66.

4. Haas, W., 1968. Das Alt-Paläozoikum von Bithynien (Nordwest Türkei). Neues Jahrbuch für Geologie und Paläontologie Abhandlungen 131, 178-242.

5. Kaya, O., 1973. Paleozoic of İstanbul. Ege Üniversitesi Fen Fakültesi Kitaplar Serisi 40, 143.

6. Olempska, E., 2002. The Late Devonian Upper Kellwasser Event and Entomozoacean Ostracods in the Holy Cross Mountains, Poland, Acta Palaeontologica Polonica, 47 (2), 247-266.

7. Göncüoğlu, C., Kozur, H.W., 1998. Facial Development and Thermal Alternation of Silurian Rocks in Turkey. In: GUITERREZMARCO J.C. \& RABANO I. (eds), Proceedings, 1998 Field-Meeting, IUGS Subcommission on Silurian Stratigraphy, Temas GeologicoMineros ITGE 23, 87-90.

8. Göncüoğlu, C., Kozur, H.W., 1999. Remarks on the pre-Variscan development in Turkey. In: Linnemann, U., Heuse, T., Fatka, O., Kraft, P., Brocke, R.\& Erdtmann, B.T. (eds) Prevariscan Terrane Analyses of "Gondwanean Europa". Proceedings, Schriften des Staatlichen Museums Mineralogie Geologie Dresden 9, 137-138

9. Gedik, İ., Önalan, M., 2001. Çamdağ (Sakarya İli) Paleozoyik Stratigrafisine ait yeni Gözlemler. İstanbul Üniversitesi Yerbilimleri Dergisi 14, 61-76.

10. Gedik, İ., Pehlivan, Ş., Timur, E., Duru, M., Altun, İ., Akbaş, B., Özcan, İ., Alan, İ. 2005. Kocaeli Yarımadası'nın Jeolojisi. MTA, Rapor No 1000774, Ankara.

11. Okay, A.C., 1947. Geologische und Petrographische Untersuchung des Gebietes Zwischen Alemdağ, Karlıdağ und Kayışdağ in Kocaeli (Bithynien Türkei). Rev. Fac. Sci. I'Univ. d'Istanbul, ser. B, t. II, fasc. 4, istanbul.

12. Önalan, M., 1982. Pendik Bölgesi ile Adaların Jeolojisi ve Sedimenter Özellikleri. Doçentlik Tezi, İstanbul Üniversitesi, İstanbul-Türkiye. 
13. Önalan, M., 1987/1988. İstanbul Devoniyen Çökellerinin Sedimenter Özellikleri. İstanbul Üniversitesi Yerbilimleri Dergisi 6, 93-108.

14. Walliser, O.H., 1996. Global Events in the Devonian and Carboniferous, Global Events and Event Stratigraphy in the Phanerozoic, 225-250.

15. Paeckelmann, W., 1938. Neue Beitraege zur Kenntnis der Geologie, Palaeontologie und Petrographie der Umgegend von Konstantinopel. 2. Geologie Thraziens, Bithyniens und der Prinzeninseln. Abhandlungen der Preussisch Geologischen Landesanstalt, N.F. 186, $1-202$.

16. Paeckelmann, W., 1925. Beitrage zur Kenntnis der Devons am Bosporus, Insbesondere in Bithynien. Abh. Preussische GeoL Landesanstalt N.F., 98, 150.

17. Rabien, A., 1954. Zur Taxionomie und Chronologie der oberdevonischen Ostracoden. Abhandlungen des Hessischen Landesamtes für Bodenforschung 9, 1-268.

18. Baykal, F., Kaya, O., 1963. Allgemeine Stratigraphie des Karbons in der Umgebung von Istanbul. Bull. Min. Res. Exp. 61, 1-10.

19. Abdüsselamoğlu, Ş., 1963. Nouvelles Observations Stratigraphiques et Paléontologiques Sur les Terrains Paléozoiques Affleurant a l'est du Bosphore. MTA Bulletin 60, 1-6.

20. Çapkınoğlu, Ş., 1997. Conodont Fauna and Biostratigraphy of the Famennian of Büyükada, İstanbul, Northwestern Turkey. Bollettino della Società Paleontologica Italiana 35, 165-185.

21. Çapkınoğlu, Ş., 2000. Late Devonian (Famennian) Conodonts from Denizliköyü, Gebze, Kocaeli, Northwestern Turkey. Turkish Journal of Earth Sciences 9, 91-112.

22. Çapkınoğlu, Ş., 2005a. Famennian Conodonts from the Ayineburnu Formation of the İstanbul Zone, NW Turkey. Geologica Carpathica, 56, 2, 113-122.

23. Çapkınoğlu, Ş., 2005b. Upper Devonian (Upper Frasnian-Lower Famennian) Biostratigraphy of the Ayineburnu Formation, İstanbul Zone, NW Turkey. Geologica Carpathica 56 (3), 223-236.

24. Göncüoglu M.C, Turhan N., Tekin U.K., 2003. Evidence for the Triassic Rifting and Opening of the Neotethyan Izmir-Ankara Ocean, northern edge of the Tauride-Anatolide Platform, Turkey. Bull. Soc. Geol. It., Spec. Vol., 2: 203-212.

25. Dojen, C., Özgül, N., Göncüoğlu, Y., Göncüoğlu, C., 2004. Early Devonian Ostracodes of Thuringian Ecotype From NW Anatolia (Turkey). Neues Jahrbuch für Geologie und Paläontologie Monatshefte 12, 733-748.

26. Yalçın, M.N., Yılmaz, İ., 2010. Devonian in Turkey-a Review. Geologica Carpathica, 61, 3, 235-253.

27. Saydam-Demiray, D.G., Çapkınoğlu, Ş., 2012. Conodont Fauna and Biostratigraphy of the Early-Middle Devonian Units in Beykoz, Şile and Kurtdoğmuş areas, İstanbul, Turkey. Bulletin of the Mineral Research and Exploration 145, 1-21.

28. Schindler, E., Nazik, A., Haude, R., Brocke, R., Şeker, E., Bozdoğan, N., Sancay, R.H., Groos-Uffenorde, H., Jansen, U., Weddige, K., Özkan, R., Yalçın, M. N., Wehrmann, A., Wilde, V., 2014. First Record of Loboliths in Turkey: Scyphocrinoids and Other Palaeontological Evidence for the Silurian/Devonian Boundary Interval in the Eastern and Central Taurides. $67^{\text {th }}$ Geological Congress of Turkey, 704-705, Ankara.

29. Jansen, U., Nazik, A., Nalcıŏglu, G., Özkan, R., Groos-Uffenorde, H., Şeker, E., Brocke, R., Sancay, R.H., Bozdoğan, N., Yılmaz, İ., Yalçın, M.N., Schindler, E., 2014. New Paleontological Data from the Devonian of Turkey and their Paleobiogeographical Implications. $67^{\text {th }}$ Geological Congress of Turkey, 674-675, Ankara.

30. Kaya, O., 1971, İstanbul'un Karbonifer Stratigrafisi: Türkiye Jeol. Kur. Bült., 14, 143 199.

31. Nazik, A., Groos-Uffenorde, H., 2009. KB Türkiye'de Frasniyen (Geç Devoniyen) Entomozoacean Ostrakodlarının ilk Bulguları. 62. Türkiye Jeoloji Kurultayı Bildiri Özleri Kitabı, Cilt II, 666-667, Ankara.

32. Nazik, A., Çapkınoğlu, Ş., Olempska, E., Özgül, N., Şeker, E., 2015. Ludlow (Silürian) and Givetian (Devonian) Ostrakods and Conodonts from the Istanbul Zone (Kartal and 
Tuzla Peninsula), NW Anatolia. In: Perrier, V. \& Meidla, T. (eds). Abstracts, 8th European Ostracodologists' Meeting. Tartu, Estonia, 2230 July 2015. Tartu, 2015, 55.

33. Nazik, A., Groos-Uffenorde, H., 2011. First Records of Late Devonian Entomozoacean Ostracodes in NW Turkey Turkish Journal of Earth Sciences20, pp.167-178.

34. Nazik, A., Şeker, E., 2011. Devoniyen Ostrakodlarının Stratigrafik, Paleoekolojik ve Paleoçoğrafik Önemi: İstanbul Zonu ve Toroslardan Örnekler, 12. PaleontolojiStratigrafi Çalıştayı Bildiri Kitapçı̆̆ı, 34, Muğla.

35. Nazik, A., Şeker, E., 2015. Ostrakod Kavk1 Morfolojisi ve Ortamsal Yorum: Devoniyen ve Miyosen Ostrakodları, 16. PaleontolojiStratigrafi Çalıştayı Bildiri Kitapçığı, 101-108, Rize.

36. Nazik, A., Yalçın, M.N., Schindler, E., Wilde. V., Wehrmann, A., Haude, R., Finks, R.M., Wehrmann, A., Yilmaz, I. Brocke, R., Jansen, U., Özkan, R., Şeker, E., Groos-Uffenorde, H., Bozdoğan, N., Sancay, R.H., Nalcioğlu, G., Saydam-Demiray, G., Weddige, K., Kozlu, H., 2014. Doğu Toroslar Devoniyeni'nde Önemli Paleontolojik Bulgular. 15. PaleontolojiStratigrafi Çalıştayı Bildiri Özleri Kitabı, 4344.

37. Webster, G.D., Yilmaz, I., Kozlu, H., 2008. A New Middle Devonian Gasterocomid Crinoid from Central Turkey and Revision of the Gastrecomidae. Palaeoworld 17, 12-20.

38. Sayar, M., Pamir, H., 1933. Küçükçekmece Fosil Fıkralı Hayvanlar Mecmuası: İst. Darıl. Jeol. Enst. Neşr., 8.

39. Şeker, E., Nazik, A., 2015. KB Türkiye (Şileİstanbul) Entomozoacean Ostrakodları, Doğu Anadolu Jeoloji Sempozyumu Bildiri Özleri Kitab1, Van, 86-87.

40. Gooday, A.J., 1983. Entomozoacean Ostracods from the Lower Carboniferous of SouthWestern England, Palaeontology 26, 755-588.

41. Önalan, M., 1990. İstanbul Devoniyen İstifindeki Yumrulu Kireçtaşlarının Oluşumu, MTA Derg., 111, 37-46.

42. Bozdoğan, N., Sancay, R.H., Nalcıŏlu, G., Saydam-Demiray, G., Weddige, K., Kozlu, H., 2014. Doğu Toroslar Devoniyeni'nde Önemli
Paleontolojik Bulgular. 15. PaleontolojiStratigrafi Çalıştayı Bildiri Özleri Kitabı, 4344.

43. Ketin, İ., 1953. Tektonische Untersuchungen auf den Prinzeninseln nahe istanbul. Geol. Rundschau, Band 41, pp. 161-172.

44. Altınlı, İ.E., 1951. Geology of the Kayışdağ Region, IÜFFM B, 16, 189-205.

45. Abdüsselamoğlu, M.Ş., 1977. The Palaeozoic and Mesozoic in the Gebze Region: Excursion Guidebook. $4^{\text {th }}$ Colloquium on Geology of the Aegean Region. Excursion 4: Western Anatolia and Thrace. ITU Maden Fak. Publication, Istanbul, 1-16.

46. Noble, P.J., Tekin, U.K., Gedik, İ., Pehlivan, Ş., 2008. Middle to Upper Tournasian Radiolaria of the Baltalimani Formation, İstanbul, Turkey. Journal of Paleontology 82, No. 1, 37-56.

47. Bless, M.J.M., Crasquin, S., Groos-Uffenorde, H., Lethiers, F., 1986. Late Devonian to Dinantian Ostracodes (Comments on Taxonomy, Stratigraphy and Paleoecology). Annales de la Société Géologique de Belgique $109,1-8$.

48. Groos-Uffenorde, H., Lethiers, F., Blumenstengel, H., 2000. Ostracodes and Devonian Stratigraphy. Courier Forschungsinstitut Senckenberg 220, 99-111.

49. Casier, J.-G. 1975. Les Ostracodes des Schistes à Aspect «Matagne» de la Partie Supérieure du Frasnien de l'affleurement Protègede Boussuen-Fagne, Belgique. Bull. Kon. Belg. Inst. Natuurwet. Aardwet. = Bull. - Inst. r. sci. nat. Belg., Sci. Terre 51(9): 33.

50. Becker, G., 1982. Ostracoda aus Cephalopoden-Fuhrendem Oberdevon im Kantabrischen Gebirge (N-Spanien). 2. Bairdiacea, Cytheracea und Entomozoacea. Palaeontographica A 178, 109-182.

51. Groos-Uffenorde, H., 1994. Late Famennian ostracodes from the Refrath 1 Borehole (Bergisch Gladbach-Paffrath Synclina; Ardennes-Rhenish Massif, Germany). Courier Forschungsinstitut Senckenberg 251, 185-235.

52. Groos-Uffenorde, H., Lethiers, F., Blumenstengel, H., 2000. Ostracodes and Devonian Stratigraphy. Courier Forschungsinstitut Senckenberg 220, 99-111. 
53. Becker, G., Bless, M.J.M., 1990. Biotope Indicative Features in Palaeozoic Ostracods: a Global Phenomenon. In: R. Whatley \& C. Maybury (eds) Ostracoda and Global Events. 421-436. British Micropalaeontological Sociev Publication Series. Chapman \& Hall. Cambridge.

54. Becker, G., Blumenstengel, H., 1995. Ostracoden vom Thüringer Ökotyp aus der Postriff-Kappe des Rü- Beländer Riffs (Elbingeröder Komplex, Harz; Obere crepidaZone, Oberdevon). Abhandlungen und Berichte für Naturkunde 18, 63-101.

55. Bless, M.J.M., 1983. Late Devonian and Carboniferous Ostracode Assemblages and Their Relationship to the Depositional Environment. Bulletin de la Société Belge de Géologie 92, 31-52.

56. Perrier, V., 2007. Biodiversité et Écologie des Ostracodes Myodocopes (Crustacea) du Silurien Supérieur d'Europe. Unpublished PhD thesis, Faculty of Science Lyon 1, UMR 5125 PEPS, 2 Volumes, 534 pp.

57. Perrier V., Vannier, J., Siveter D.J., 2007. The Silurian Pelagic Myodocope Ostracod Richteria Migrans. Transactions of the Royal Society of Edinburgh, Earth Sciences 98, 1-13.

58. Groos-Uffenorde, H., Lethiers, F., Blumenstengel, H., 2000. Ostracodes and Devonian Stratigraphy. Courier Forschungsinstitut Senckenberg 220, 99-111.

59. Pribyl, A., 1950. On the Bohemian Ostracoda of the Families Entomozoidae and Entomoconchidae. Bulletin Scientifique

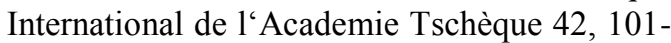
128.

60. Gozalo, R., 1994. Geologỉa y Paleontologỉa (Ostrácodos) del Devónica Superior de Tabuenca (NE de la Cadena Ibérica Oriental). Memorias del Museo Paleontológico de la Universidad de Zaragoza 6, 1-291.

\section{Levha 1}

1, 2. Entomoprimitia nitida (F.A. Roemer, 1850)

1 .Ed-7, 2. Ed-6

3, 4. Entomoprimitia sartenaeri Casier, 1975

3. Ed-7, 4. Ed-8

5, 6. Entomoprimitia kayseri Waldschmidt 1885
5. Ed-7, 6. Ed-7

7, 8. Franklinella calcarata (Reinh. Richter,1856)

7. Ed-6, 8. Ed-6

9, 10. Richterina (Volkina) zimmermanni (Volk, 1939)

9. Ed-7, 10. Ek-1

11, 12. Nehdentomis pseudorichterina

(Matern,1929)

11. Ed-7, 12. Ed-6

13. Entomoprimitia concentrica Matern 1929

Ed-6

14. Rabienella n.sp. c, aff. reichi sensu Rabien \& Rabitz, 1958

Ed-3

15. Kuzminella sp. sensu Olempska 1993

Ed-7

Levha 2

1. Entomoprimitia kayseri Waldschmidt 1885

Ed-9

2. Waldeckella erecta Rabien, 1954

Ek-2

3. Rabienella reichi (Matern,1929)

Ed-3

4, 5. Entomoprimitia sartenaeri Casier, 1975

4. Ed-7, 5. Ed-7

6. Richterina (Volkina) zimmermanni (Volk,1939)

Ek-1

7, 8, 9. Franklinella calcarata (Reinh. Richter, 1856)

7. Ed-7, 8. Ed-6, 9. Ed-7

10, 11, 12. Nehdentomis pseudorichterina (Matern,1929)

10. Ek-3, 11. Ed-6, 12. Ek-2

13. Entomoprimitia concentrica Matern 1929

13. Ed-7,

14, 15. Tentakülit

14. Ek-2, 15. Ek-1 


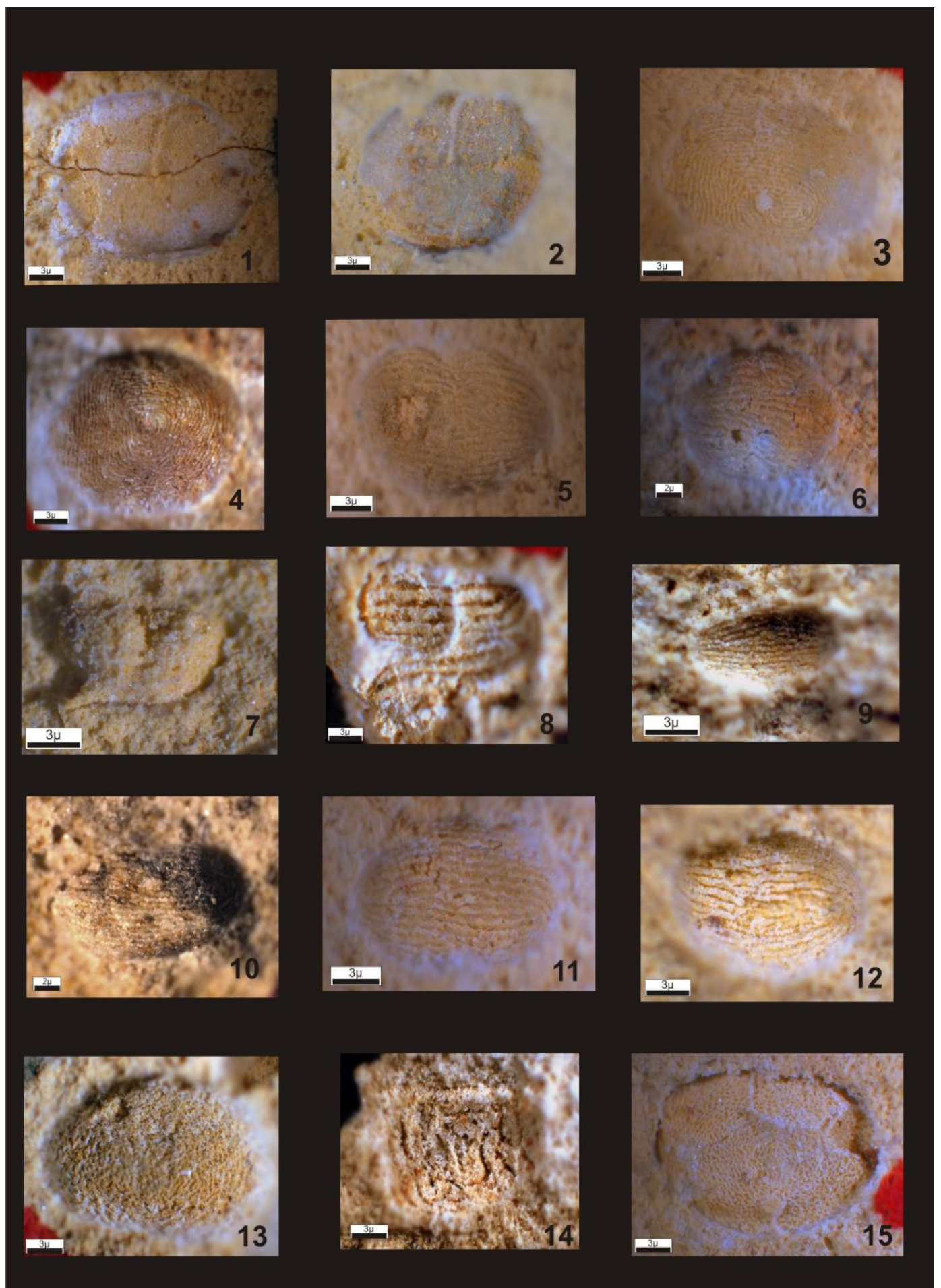

Levha 1 


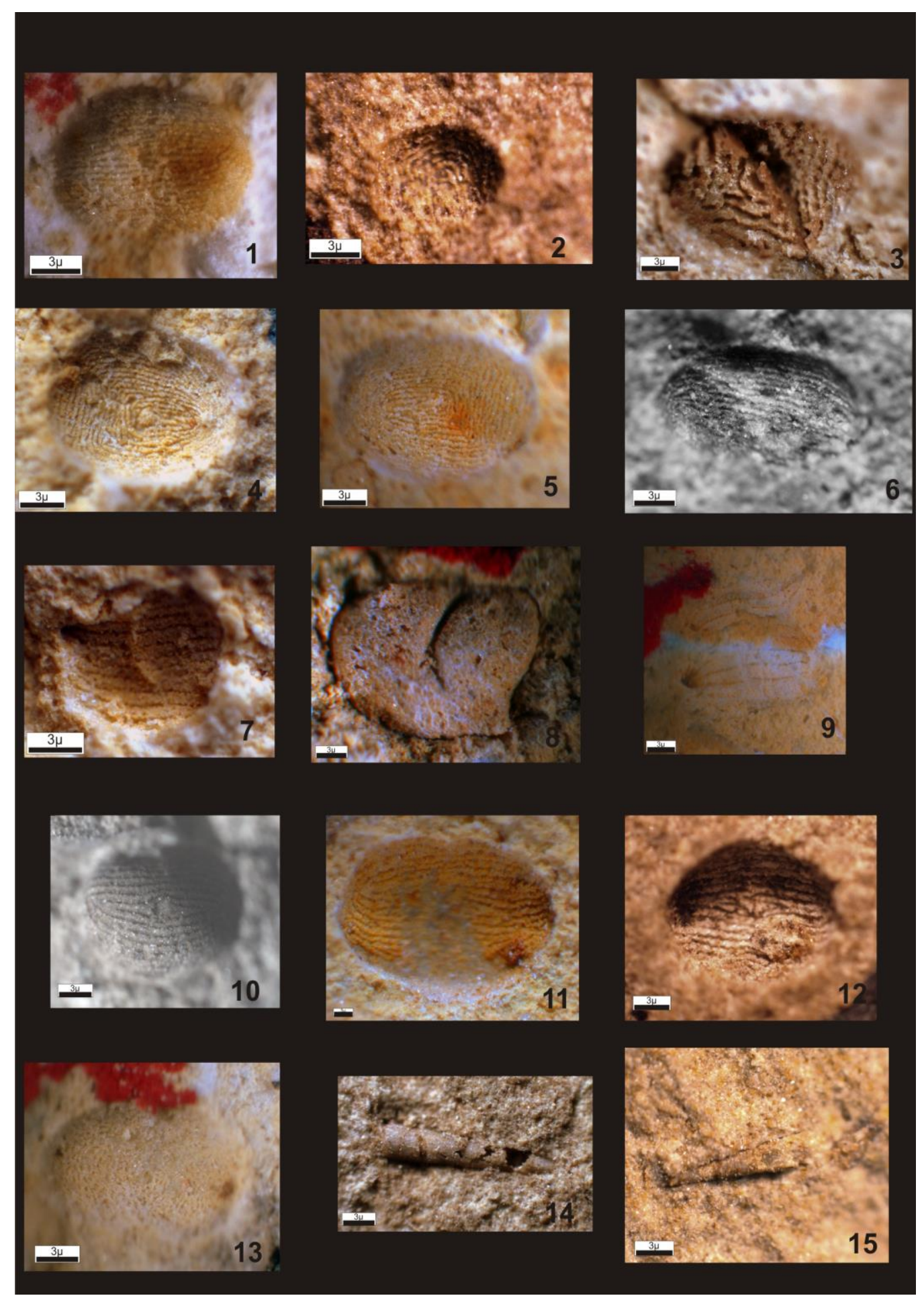

Levha 2 